\title{
AC 2007-1541: USING PHENOMENOGRAPHY TO INVESTIGATE DIFFERENT WAYS OF EXPERIENCING SUSTAINABLE DESIGN
}

\section{Llewellyn Mann, University of Queensland}

LLEWELLYN MANN is a PhD student in the School of Engineering at the University of Queensland and a member of the Catalyst Research Centre for Society and Technology. He has a Bachelor of Engineering (Mechanical \& Space) and a Bachelor of Science (Physics) from UQ, as well as a Graduate Certificate of Education (Higher Education). Major research interests include; Engineering Education, Sustainability, Teaching and Learning, Engineering Design, Technology and Society.

\section{Gloria Dall'Alba, University of Queensland}

GLORIA DALL'ALBA teaches and researches in the area of teaching and learning in higher education in the School of Education at the University of Queensland, Australia. She has a particular interest in professional education, learning in the workplace, and questions of research methodology. She has published articles in international journals such as Learning and Instruction, International Journal of Educational Research, and Studies in Higher Education. A forthcoming book, Learning to be a professional, will be published by Springer. She is guest editor for a special edition of the journal, Educational Philosophy and Theory, on phenomenology and education.

\section{David Radcliffe, University of Queensland}

DAVID RADCLIFFE is the Thiess Professor of Engineering Education and Professional Development in the School of Engineering at the University of Queensland. His research draws on and involves collaboration with the social sciences including education and anthropology. David is co-director of the Catalyst Centre and Director of Professional Development in the School. He was a National Teaching Fellow, in 1994 and a Boeing-A.D. Welliver Fellow, in 1999. 


\section{Using Phenomenography to Investigate Different Ways of Experiencing Sustainable Design}

\section{Introduction}

This paper reports research conducted on the variation in experiences of sustainable design in practice. The experiences with sustainable design of a group of twenty-two engineers and nonengineers were investigated empirically. This revealed five qualitatively different ways of experiencing sustainable design. These have implications for both improving future practice, and the education of students about sustainable design.

All Australian engineering graduates are now expected to have a working understanding of sustainable design. This is not merely an expectation of professional institutions that accredit engineering programs ${ }^{1}$, nor is it only limited to a few specific disciplines within engineering, but increasingly it is an expectation of the engineering workplace ${ }^{2,3}$ as well as the wider society ${ }^{4}$. This expectation presents a series of motivations for investigating experiences of sustainable design to aid in improving both practice and education. To find out how to educate engineering students, we need first to find out what current professional engineers' experiences of sustainable design are. Engineering education is a professional education, and thus aims to enable students to engage in practice in ways characteristic of competent engineering practitioners ${ }^{5}$. We cannot simply rely on academics' current knowledge or the current literature on sustainable design to inform educational processes, as the practice of sustainable design is changing at an ever increasing pace 6 . We must turn to the people who are having both to deal with sustainable design on a daily basis, and who are recognized as leaders in the field, namely the practitioners of sustainable design ${ }^{7}$. Further, we need to stretch the horizons of current engineering practice, and include both engineers and non-engineers. While all still involved with engineering design activities, these practitioners are not confined to a 'culture' of engineering practice and can offer different insights into and perspectives of what sustainable design is and could be.

The fundamental problem with sustainable design in practice is that, like many aspects of professional practice, different people and different groups have different views of what sustainable design is. There is no commonly agreed to or shared understanding of what sustainable design means, and how it is operationalised in practice ${ }^{8,9}$. One reason for this is that everyone's own understanding is influenced by their own particular background, previous training, work experience and their political and economic ${ }^{10}$. These different views need to be identified in order to improve both the practice and the education of sustainable design.

The purpose of this research was to examine variations in the experiences of sustainable design among professionals involved in engineering design activities, including both engineers and nonengineers, using a phenomenographic approach ${ }^{11}$. The emphasis is on the experiences of practitioners of sustainable design all with experience in engineering operations ${ }^{7}$. These practitioners not only have to deal with sustainable design issues on a daily basis and so have many experiences to draw upon, but are also generally more aware of the current trends and applications of sustainable design in practice than other groups, such as engineering academics or policy makers. 
Specifically, the questions for the research were:

1. What are the variations in ways of experiencing 'sustainable design' among sustainable design practitioners?

2. What are the implications of this variation for the practice of sustainable design?

3. What are the implications of this variation for the education of future professional engineers about sustainable design?

This paper focuses on describing the phenomenographic study, including the actual processes undertaken in this research. An overview of phenomenographic approach in general is also provided, in order to discuss the wider use of phenomenography within engineering education research. While the paper does present the results of the research, in the form of a set of five ways of experiencing sustainable design, this paper does not explore these results in depth (this is presented in ${ }^{12}$ ). The validity and reliability of the results is discussed. Some implications for the education of future professional engineers about sustainable design are presented.

\section{Background}

In a university setting, engineering education's main objective is to produce engineering graduates that can engage in practice as competent professionals ${ }^{13}$. Traditionally, both formal university education and professional development have entailed defining specific attributes, including knowledge, skills, attitudes and values ${ }^{13,14}$. Education is seen as the cumulative acquisition of these attributes, also known as skills development ${ }^{15,16}$. An alternative view to professional development is based on the existence of different ways of experiencing practice ${ }^{13,}$

17. "The knowledge and skills that make up professional practice are organized within an understanding of that practice" ${ }^{\prime 18}(\mathrm{p} 680)$. Thus professional education is seen as both enriching experiences of engineering practice ${ }^{5}$, as well as developing skills within the context of practice ${ }^{17}$. These combine to form a 'professional way-of-being'.

In the past, "changes in curricula initiated by educational institutions, have ranged from little, to course adaption, to a few bold efforts to equate education to the new situation [of sustainability]" ${ }^{19}$ (p90). Sustainable design education at university is often seen as an add-on to existing engineering courses and programs, rather than an integral part of the curriculum ${ }^{20-22}$. A reason for this approach often cited is the belief that little could be left out of existing curricula to make room for new courses on sustainability and sustainable design ${ }^{19}$. While some universities in Australia have made efforts at embedding sustainability and sustainable design at the core of their engineering curricula, these are usually only in one or two specific disciplines, rather than across all engineering ${ }^{4,19}$.

The traditional approach in engineering education takes a reductionist approach, separating content, in the form of knowledge, skills and values, from professional practice ${ }^{13,23}$. Prevailing theories of professional learning see practice as a 'container' for particular forms of social interaction and having an "objective structure consisting of institutionalized social rules and norms" ${ }^{13,24}$. When seen in this way, it is possible to decontextualise content from practice, and study the two independently. The decontextualised content becomes the basis of formal education programs. Further, in current engineering education, the content is not only decontextualised, but fragmented into specific discipline and subject areas. So for instance mechanical engineering 
students do not learn about the practice of mechanical engineering, but learn fragmented subjects such as mechanics, dynamics, thermodynamics, fluid mechanics and design, without an understanding of how they relate to each other or to practice.

This process of decontextualisation and fragmentation is what Schön ${ }^{25}$ refers to as the 'normative professional curriculum': first, teach students the relevant basic science, second, teach them the relevant applied science, and third, "give them a practicum in which they can learn to apply classroom knowledge to problems of everyday practice". The discrepancy between "scientific knowledge' taught in engineering programs and knowledge valued by practitioners is highlighted again by Schön ${ }^{25,26}$. He identifies that most knowledge in practice is 'knowledge-in-action' and includes tacit knowledge, skills and attitudes that cannot be separated from each other or the professional action. As $\operatorname{Schön}^{25}$ (p30) remarks:

If a skilled performer tries to teach (and therefore, in part, describe) her knowing-in-action to someone else, she must first discover what she actually does when confronted with a situation of a particular kind. So... a calculus teacher might have to 'see what he does' when he is asked to say how he sets up a problem of differentiation or integration... If we want to discover what someone knows-in-action, we must put ourselves in a position to observe her in action. If we want to teach our 'doing', then we need to observe ourselves in the doing, reflect on what we observe, describe it, and reflect on our description.

Knowledge, skills, attitudes and values are all vital parts of a professional education such as engineering, and combine in an integrated sense to form engineering skills. These engineering skills are not specific traditional skills, but broader engineering skills such as problem solving or design. Skill development in traditional professional education is seen as the progressive, stepwise accumulation of knowledge, skills, attitudes and values. However "practitioners cannot meaningfully be separated from their activities and the situations in which they practice"

${ }^{13}$ (p413). Content and practice cannot be separated and taught independently and still produce the level of skill that is aimed for ${ }^{27}$. Further, empirical research ${ }^{28}$ has found that practice varies across contexts, as does what is regarded as skilled performance ${ }^{17}$. Viewing learning as filling up with knowledge fails to address the way in which the learning content is experienced by the learners, identified as critical to learning $5,13,29,30$.

\section{A Model for Sustainable Design Education}

The goal of engineering education is to develop and broaden students' experiences of the field of engineering, along with the meaning those experiences have for them ${ }^{5}$. These two aspects, experiences and their meaning, must be developed concurrently, as both are necessary for practice as a competent practitioner. For this to happen, engineering programs and courses must provide students with experiences to both develop their level of skill, along with their way of experiencing practice $e^{5,17}$.

It is argued that professional development is not a stepwise process of moving through fixed sequences of stages as normally understood ${ }^{15,16}$, but rather one of continual development. Further, the focus on moving through a fixed sequence of stages takes attention away from developing understanding of, and in, practice ${ }^{17}$. "Understanding is not seen here as limited to cognitive content or activity; rather... [it] is embedded in dynamic, intersubjective practice... [and] integrates knowing, acting, and being" (p388-389). This embodied understanding, what 
Dall'Alba ${ }^{18}$ describes as an unfolding professional way-of-being, forms the basis of professional development. "Professionals not only learn knowledge and skills, but these are renewed over time while becoming integrated into ways of being the professional in question" ${ }^{17}$ (p389).

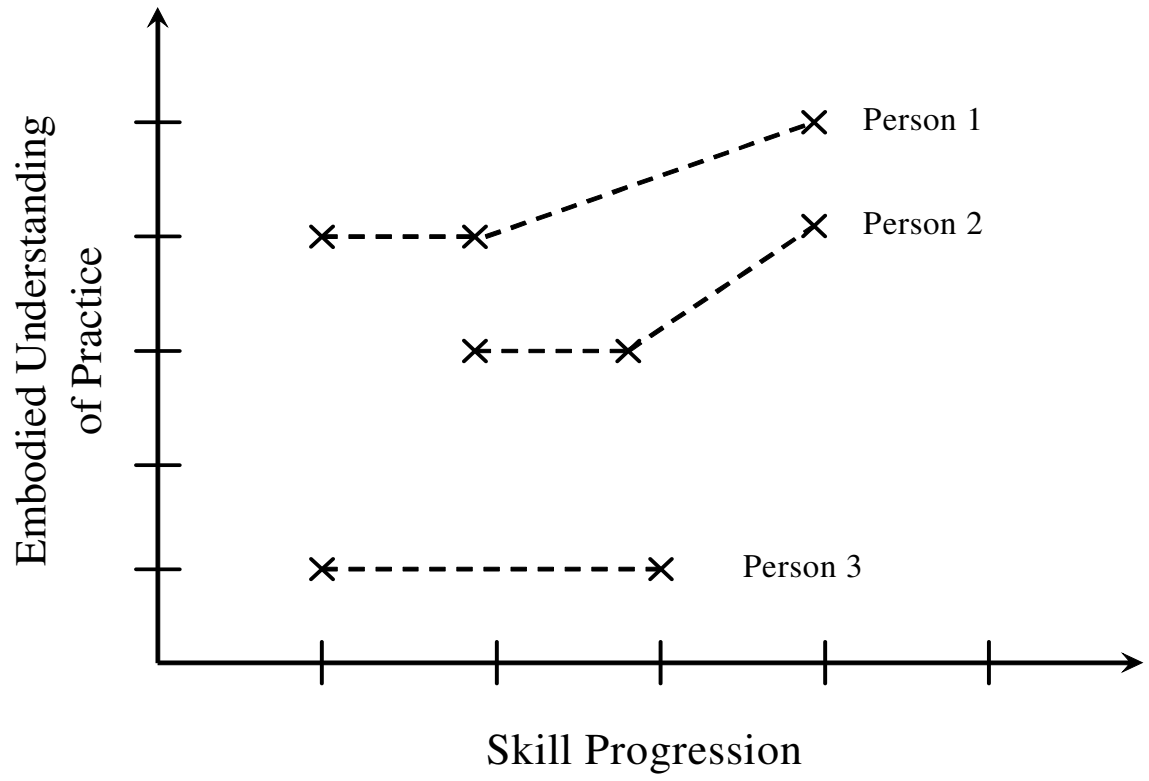

Figure 1: Model of Professional Development ${ }^{17}$

The different ways of experiencing practice are central to how practitioners perform in and develop their own practice ${ }^{18}$. This notion of differing ways of experiencing practice, along with skill progression, forms the basis of a new model of professional development ${ }^{17}$. The model is presented diagrammatically in Figure 1, with illustrations of some possible trajectories of development. The horizontal axis of Figure 1 shows skill progression, such as the use of computer-aided design or engineering problem solving. These skills are the skills that allow an engineer to effectively act in practice. This progression can also be linked to increasing experience with the skill that is being developed ${ }^{17}$. While it does not follow a fixed sequence of steps, points can be identified along this axis similar to the stages Dreyfus ${ }^{15}$ identifies; those of novice, advanced beginner, competent, proficient and expert. These can be used to determine where practitioners are in their skill development for the assessment of professional development. The vertical axis represents qualitatively different ways of experiencing practice. "In any one social, historical, and cultural context, there are likely to be a limited number of qualitatively different ways in which a particular practice is understood and carried out"17 $(\mathrm{p} 400)$.

From this model of professional development, learning is seen as moving along both axes in some way within a particular practice context. This could be as: (i) moving from less comprehensive to more comprehensive ways of experiencing aspects of practice (moving vertically), while integrating current skills ( $\mathrm{x}$ axis) into this new way of experiencing. (ii) Developing more advanced skill levels (moving horizontally), while integrating this into an existing way of experiencing (y axis). For instance, "some professionals may devote most of their working lives to refining an existing understanding, making considerable progress along the horizontal dimension with limited change on the vertical dimension" ${ }^{, 17}$ (p400-401). (iii) A combination of both, developing more advanced skills and more comprehensive ways of 
experiencing practice (moving diagonally). The model also acts as a way of organising knowledge, skills, attitudes and values within an understanding of practice.

An implication of this model is that if the different ways of experiencing practice are not taken into account in formal education, either at university or in a professional context, then students and practitioners will continue to learn content and skills within their less comprehensive way of experiencing practice ${ }^{5}$. If this model is to be used in sustainable design education, the different ways of experiencing sustainable design must be identified.

\section{Overview of Phenomenography}

\section{History of Phenomenography}

Phenomenography is the empirical study of the qualitatively different ways in which aspects of the world are experienced. That is, it involves mapping phenomena, or the relations between persons and aspects of their world ${ }^{31}$. It is a qualitative research approach first used in the original work of the Swedish researchers Ference Marton ${ }^{32-34}$, Roger Säljö ${ }^{35,36}$, Lennart Svensson ${ }^{37}$ and Lars-Öwe Dahlgren ${ }^{38}$ in the mid-70s. Phenomenography was initially developed to investigate learning among university students, leading to identifying the 'surface' and 'deep' approaches that are widely known in education circles today ${ }^{32}$. Phenomenography appeared in its own right as a research approach for describing people's experiences during the early 1980's (see for example Marton ${ }^{33,39}$ ). It is important to note that, historically, it was an empirical approach, and only more recently research has been conducted to elaborate the underpinning theory ${ }^{40,41}$. Historically, phenomenography has been used to research the experience of learning, the experience of teaching, the different ways of experiencing the content learned, and describing aspects of the world around us ${ }^{42}$. The research described in this paper used developmental phenomenography, in that it examines sustainable design practitioners' ways of experiencing sustainable design, in order to better inform current practice, as well as to help educate future engineering students about sustainable design.

\section{Object of Study}

The object of research in phenomenography is the variation in the ways of experiencing different aspects of the world ${ }^{11}$. It is about describing the world as experienced, and revealing and describing the variation that exists ${ }^{43}$. Figure 2 illustrates this focus of phenomenography, not on specific aspects of the world, or the subjects themselves, but on the relationships between them. Hence, phenomenography takes the position that experience is relational, not purely objective, independent of people, nor purely subjective, independent of the world. Knowledge is then created from the relations between persons and in relation to the world. As Marton \& Booth explain, with reference to a learner ${ }^{11}$ (p13):

There is not a real world 'out there' and a subjective world 'in here'. The world [as experienced] is not constructed by the learner, nor is it imposed upon her; it is constituted as an internal relation between them. There is only one world, but it is a world that we experience. 


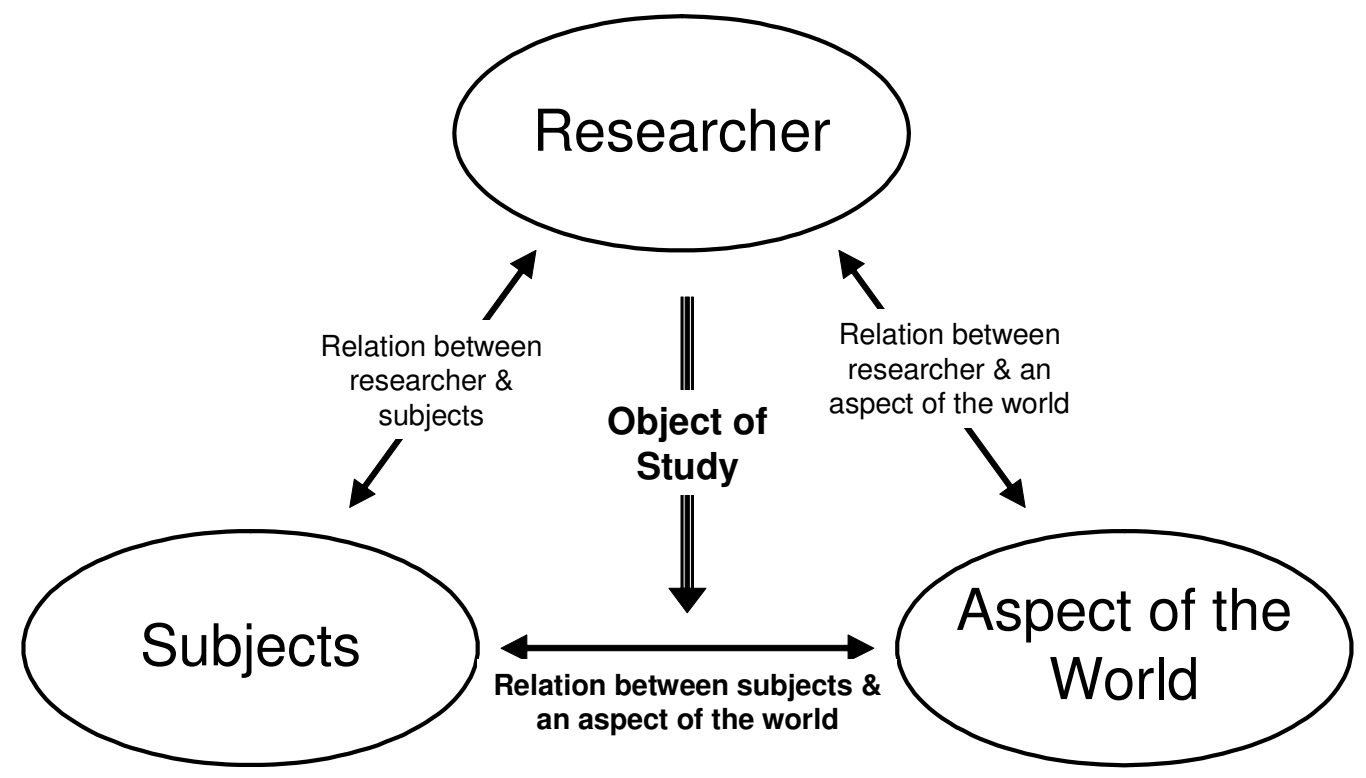

Figure 2: Focus of Phenomenographic Research ${ }^{43}$

They go on to argue that this applies specifically to describing the world around us, using an analogy of the Big Bang (p113):

We cannot describe a world that is independent of our descriptions or of us as describers. We cannot separate out the describer from the description. Our world is a real world, but it is a described world, a world experienced by humans. Quite obviously, humans did not cause the Big Bang, but the way in which it is conceptualized and described is a human way of conceptualizing and describing it. The implication of this is not necessarily that our way of understanding the Big Bang is flawed or distorted, but that it is partial. Furthermore, the human mind can hardly conceive of what it would take to conceive of the Big Bang through means other than the human mind.

The focus on the world as experienced gives phenomenography a non-dualist ontology. It takes neither a positivist/objective approach, independent of human interpretation, nor does it take a subjectivist approach, focusing on internal constructions by the subject ${ }^{11,44}$. We are not interested only in what people think per se, but instead what their experiences are and have been in situations where they have had to deal with aspects of the world. What people think may be clouded by rhetoric that they have been told or read, whereas their experiences reveal more about their understandings of the aspect of the world of interest. A non-dualist ontology also has implications for the relationship between the researcher and the aspect of the world under investigation, as depicted in Figure 2. This relationship is important as it allows the researcher to carry out the research, as some understanding of the research topic is needed to interpret the statements made, and to keep the research focused. However, any preconceptions or theories about the aspect of the world under consideration that the researcher has from their own experiences must be bracketed or held at bay during the research ${ }^{45}$. This allows the researcher to be open to other ways of experiencing the particular aspect of the world under study, and able to present these other experiences as genuinely as possible. Trigwell provides an overview of how phenomenography is distinguished from other research approaches ${ }^{44}(\mathrm{p} 77)$ : 
The key aspects of a phenomenographic research approach ... are that it takes a relational (or non-dualist) qualitative, second-order perspective, that it aims to describe the key aspects of the variation of the experience of a phenomenon rather than the richness of individual experiences, and that it yields a limited number of internally related, hierarchical categories of description of the variation.

These aspects and their points of departure from other research approaches can be seen in Figure 3. Phenomenography can be found along the right, with other research approaches deviating at five points of departure: (1) Phenomenography is non-dualist in that reality is seen as constituted from the relations between the individual subjects and an aspect of the world ${ }^{44}$. (2) It is methodologically qualitative as it tries to explore and describe a phenomenon in terms of the relations between persons and an aspect of the world. The categories of description are also drawn from the data, rather than trying to fit the data to predetermined categories. (3) Phenomenography takes a second order approach, as it is the experiences of others rather than the researcher, that are the base of the investigation ${ }^{44}$. (4) It focuses on the variation in the ways an aspect of the world has been experienced. As Trigwell ${ }^{44}$ points out, this is fundamentally different from other research approaches. (5) Finally, phenomenography results in a set of categories that are internally related. The focus on qualitatively describing the variations and relationships between categories of description is one of the major differences between phenomenography and other research approaches, such as alternative conceptions research ${ }^{46}$. One of the strengths of phenomenography is that it "provides a way of looking at collective human experience of phenomena holistically despite the fact that such phenomena may be perceived differently by different people and under different circumstances" ${ }^{\prime 47}(\mathrm{p} 72)$.

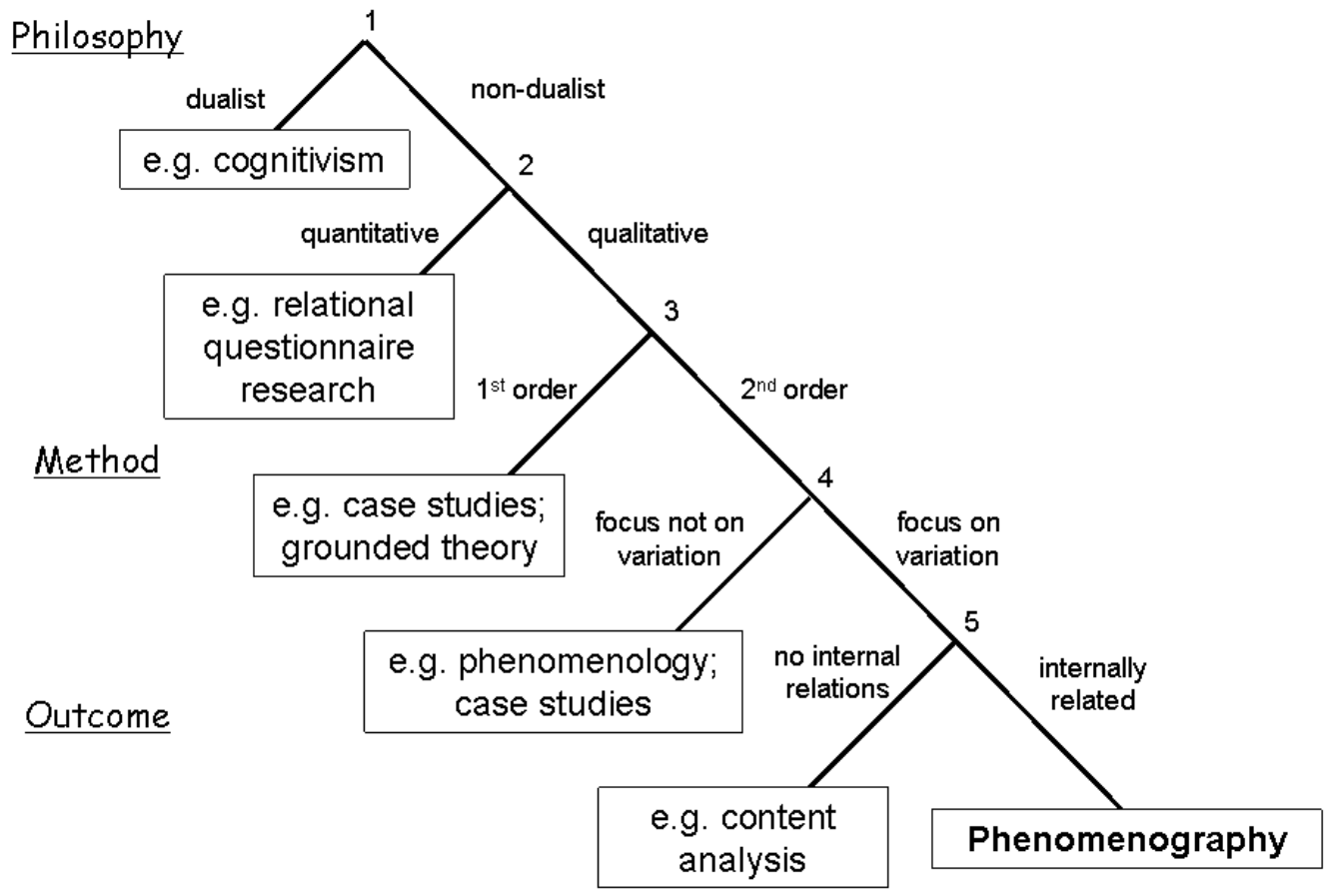

Figure 3: Points of Departure Between Phenomenography and Other Research Approaches ${ }^{44}$ 


\section{Outcomes of Phenomenography}

The major outcomes of a phenomenographic study are the description and organization of the variations in 'ways of experiencing' an aspect of the world into 'categories of description', and the organization of these categories into a hierarchy from less comprehensive to more comprehensive, referred to as an 'outcome space ${ }^{48}$. The categories of description are an attempt to clarify the different ways the same aspect of the world has been experienced by a group of people who are all highly confident that their interpretation is the most reasonable ${ }^{47}$. The hierarchical relationships between the categories are not value judgments from 'better' to "worse ${ }^{49}$. However some categories of description are inclusive of other categories and, as such, the structural relationships in a phenomenographic outcome space are those of hierarchical inclusiveness. This also leads to the structure not necessarily being linear, but instead may contain forks or branches. However, the categories of description developed can never form an exhaustive system for the aspect of the world, but they should be complete for the experiences of the group of participants under consideration at a particular point in time ${ }^{11,48}$. The following three criteria for judging the quality of the categories of description developed in a phenomenographic study are put forward by Marton and Booth ${ }^{11}$ :

1. The individual categories should each stand in clear relation to the aspect of the world under investigation so that each category tells us something distinct about a particular way of experiencing the aspect of the world;

2. The categories have to stand in a logical relationship with one another, a relationship that is frequently hierarchical;

3. The system should be parsimonious, which is to say that as few categories should be explicated as is feasible and reasonable, for capturing the critical variation in the data.

Marton and Booth ${ }^{11}(\mathrm{p} 114)$ argue that the final categories of description and the outcome space they create is a depiction of variation on a collective level, and as such, "individual voices are not heard. Moreover, it is a stripped description in which the structure and essential meaning of the ... [categories] are retained while the specific flavors, the scents, and the colors of the worlds of the individuals have been abandoned". The categories are thus not necessarily ones that any one person in 'real life' would identify with; they are constructions that incorporate key variations of discussions with a specific number of people ${ }^{50}$.

\section{Data Collection}

Phenomenographic studies need to have a coherent method throughout, from the initial planning stages through the collection of the data, to analysis. Most importantly, the research should have a clear purpose, and all efforts should be planned around that purpose ${ }^{42}$. The research subjects are identified in the planning stage of the research due to their relationship with the specific aspect of the world under consideration. They should also be selected to obtain as much variation in their experiences as possible, but still within the purpose of the study. Phenomenographic data collection usually revolves around interviews ${ }^{51}$, which have an open ended format with interviewees responding to an initial question or problem. "The researcher and researched must begin with some kind of (superficially) shared topic, verbalized in terms which they both recognize as meaningful" ${ }^{, 52}$ (p299). The purpose of the phenomenographic interviews is to reveal interviewees' experiences with the aspect of the world under consideration. As such, interviewees are encouraged throughout the interview to reflect on and reveal their way of experiencing the aspect of the world in context. What is important is what the interviewees think these experiences 
reveal about the aspect of the world itself, and follow up questions in the interview should focus on eliciting this meaning ${ }^{47}$. As Marton ${ }^{31}$ (p4427) argues "The interview has to be carried out as a dialogue, it should facilitate the thematisation of aspects of the subject's experience not previously thematised. The experiences... are jointly constituted by interviewer and interviewee."

Once the initial question or problem has been proposed, follow up questions ask interviewees to elaborate on their experiences and what they mean by certain concepts. All follow up questions are extracted from what the interviewee has said so far in the interview, and not formed through predetermined ideas and questions from the interviewer. As such, different interviews "may follow somewhat different courses"39 (p42). In this way, the interview is a dialogue or conversation, encouraging the interviewees to reflect on their experiences of the aspect of the world. Judgmental comments from the interviewer should never be made in the interview ${ }^{43}$.

An important aspect of the phenomenographic interview is the use of empathy to further engage with subjects' life-worlds ${ }^{52}$. As the categories of description are derived from subjects' experiences relayed in the interview, it is "a paramount requirement for phenomenography to be sensitive to the individuality of conceptions of the world" 52 (p297). This is achieved through the process of 'bracketing' the interviewer's own assumptions and theories, and instead being empathetic to the subjects' experiences of the aspect of the world under consideration. Three of the presuppositions that need to be bracketed which have been identified by Ashworth \& Lucas ${ }^{52}$ are: (i) importing earlier research findings; (ii) assuming pre-given theoretical structures or particular interpretations; and (iii) imposing the investigator's personal knowledge and belief. In order to help bracket these presuppositions during the interview, the interviewer needs to achieve a level of empathy with the experiences of the subjects being interviewed. While interviewers can't detach themselves from their own life-world, they do need to bracket their own theories and preconceptions, and focus on the experiences of the participant. Ashworth \& Lucas ${ }^{52}$ (p299, their emphasis) use the following to illustrate this:

For instance, views and factual claims which the student expresses in an interview may well be regarded by the researcher as quite erroneous. The temptation would be to marginalise such material. But the researcher who adopts an attitude of empathy with the student should find such views and factual claims of immense interest.

Another important aspect of the data collection process is conducting pilot interviews to enhance phenomenographic interviewing skills ${ }^{43}$, and to test if the initial questions reveal the sorts of experiences (data) necessary to address the focus of the research ${ }^{51}$. It is important that the pilot interviews are with people within the target group to obtain practice investigating the sorts of experiences that could be encountered in the final study. It is also important that they are discarded and not included in the final study ${ }^{43}$, as the interviews may contain potential errors that might invalidate the results. Also, it is often the case that the follow-up prompts are more useful in eliciting meaning than the initial planned questions ${ }^{47}$. As these follow-up questions have to be devised 'on the fly' based upon what the subjects say in the interviews, it is vital to practise identifying and asking this type of question during the pilot interviews.

Data Analysis

There is great variation in the methods used to analyze data in phenomenography. The overview presented here includes some of the customary procedures in phenomenography, and forms the 
basis of the approach used in this study. For a more detailed description of the commonalities and variations in the phenomenographic method of data analysis, see $\AA$ kerlind ${ }^{48,53}$. Interviews transcribed verbatim become the focus of the phenomenographic analysis when interviews have been used as the primary means of data collection. The set of transcripts represent a 'snapshot' of some of the experiences of a group of people with a particular aspect of the world in response to a particular set of questions at a particular time ${ }^{49}$. When data collection has relied only on interviews, no other evidence exists beyond the transcripts to inform the analysis process ${ }^{43}$.

The analysis process is both one of 'discovery" ${ }^{54}$ as well as one of 'construction' ${ }^{55}$. The results are not known in advance and tested in the study, but must be discovered, or emerge from transcripts, and constructed in an iterative way from the transcripts. In this way, phenomenographic analysis is a 'bottom up', inductive way of working from the data to the results, rather than a 'top down' way of constructing then testing an hypothesis ${ }^{51}$. It is important to keep an open mind during the analysis ${ }^{48}$. The categories of description may change several times during the analysis process, and the researcher cannot close off to already determined categories. To achieve this, a constant focus must be maintained on the transcripts as the only source of evidence. The researcher needs to focus on the transcriptions and categories as a whole set, rather than on individual transcripts or categories in isolation ${ }^{51}$. Also, the researchers' own presuppositions about the phenomenon must be set aside or bracketed ${ }^{52}$. The researcher must be open to the fact that different people may see the same phenomenon in different ways, which is an underpinning of phenomenography, but is counter-intuitive to our natural attitude ${ }^{11,43}$.

Some phenomenographers emphasize not analyzing the structural relationships between the categories until the categories themselves are finalized, as it may introduce the researcher's relationship with the phenomenon into the categories ${ }^{43,52}$. Others argue that focusing on the structure of the categories and outcome space too late could lead to the meaning and structure not being adequately co-constituted in the final outcome space ${ }^{47}$, and that a strong emphasis on looking for structure in the phenomenographic analysis process is vital, as the focus on structure:

- is an epistemological underpinning of phenomenography;

- increases the potential for practical applications from the research;

- provides a simultaneous focus on variation and commonality.

The analysis process involves identifying meaning or variation in meaning across the set of transcripts. As it focuses on describing qualitative similarities and differences across the transcripts, phenomenographic outcomes do not show the richness of the data, only variation for which there is clear evidence from the transcripts ${ }^{43}$. This focus on facets that are critical in distinguishing the variation between categories of description allows the structural relationships to be highlighted to a degree that would not be possible if "the analysis focused on every nuance of meaning" 47 (p72). The analysis process starts by the researcher reading and re-reading all the transcripts as a full set of data ${ }^{51}$. The researcher then tries to articulate the aspect of the world for each transcript. Transcripts with similar individual meanings are then grouped, with the similarities within and differences between the groups clarified. A description of each category is written with illustrative quotations from the transcripts. These descriptions form the preliminary categories for the set of transcripts. It needs to be understood that this first attempt will not necessarily be 'right' and will most likely change. It will, however, provide a different way to see the data, to then revisit and further develop the categories ${ }^{51}$. 
From the initial groups, the researcher identifies transcripts that do not seem to fit into any category, as such transcripts often show a different facet that needs to be considered. The descriptions of the categories are clarified with constant reference back to transcripts as wholes. During this process, the researcher must constantly be asking, 'Is there another way of interpreting this statement?' It is also important to constantly refer to the initial focus of the study, as it is easy to become distracted by particular aspects of the transcripts ${ }^{43}$. In writing the descriptions of the categories, researchers can only rely on what is included in the transcripts, and cannot extend or speculate on this. The researcher can accomplish this by constantly asking, 'Where in the transcripts does this come from?' almost becoming their own devil's advocate. The final descriptions of the categories should be self-contained, in that they are able to be understood as a set of separate, stand alone statements. At the end of the analysis process, all of the transcripts are sorted into individual categories of description. The categories themselves should have clearly defined statements of what they are, backed up with illustrative quotations from the transcripts. Pictorial representations may also help to explain the categories. A label for each category of description can also be developed, but this labeling should be avoided until late in analysis, as it may limit further category development ${ }^{43}$. The relationships between the categories of description should also be detailed, using illustrative quotations where appropriate. These relationships should specify the similarities and differences between the categories and help to reveal categories that are more comprehensive than others. The categories are then sorted into a hierarchy based on their increasing comprehensiveness. This hierarchical representation of the categories of description is known as an outcome space ${ }^{49}$.

\section{Investigating Practitioners' Experiences of Sustainable Design}

\section{Data Collection}

Twenty-two sustainable design practitioners were identified and interviewed. As this was an exploratory study of experiences around engineering operations, it was important that these individuals were as diverse in rich experiences of sustainable design as possible. This helped demonstrate the range of diversity of views and experiences that exist about sustainable design, even among people dealing with it on a regular basis. Diversity was also important for the research approach, as it made a larger number of qualitatively different ways of experiencing sustainable design discernible from the infinite set. It should be noted here that diversity refers to the diversity of experiences among the subjects, and not the diversity of a single subject's experiences.

The identification of sustainable design practitioners was one of the major problems recognized at the beginning of this phase of the research. The twenty-two subjects were selected as sustainable design practitioners according to three conditions:

- The extent of their sustainable design experience;

- Their proximity to engineering operations;

- Their accessibility to be interviewed.

The diversity of the subjects' sustainable design experiences was fundamental to both the research approach and the research questions. The subjects needed to have experiences with sustainable design to discuss in the interview. Many engineers do not have design experience, let 
alone sustainable design experience, so this was a necessary condition. In keeping with the phenomenographic approach, the nature of the experiences was not important, as long as the participant understood them as experiences with sustainable design.

The proximity to engineering operations was important, as one of the aims of the research was to help inform the education of future engineers about sustainable design. As such, the focus was not just on sustainable design, but on sustainable design within engineering operations; operations that engineers would be expected to work on in the future. As the subjects chosen were both engineers and non-engineers, the non-engineers were selected based on their experiences working on engineering projects.

The accessibility of prospective informants was important for the logistics of the research and the resources required. Subjects were thus chosen according to their availability and location. In many cases this restricted the focus to people within fifty kilometers of Brisbane, but did include some people from across Australia and some with international experience.

The subjects were in a sequential manner, based partially on how much they broadened the diversity of the group, as well as the depth of experiences that they had. A purposeful sampling technique $^{56-58}$ was used as a basis for the selection ${ }^{58}$. This involved looking for people who were recognized as leaders in sustainable design practice, either through winning awards, working on particularly 'sustainable' projects, or just by word of mouth and reputation. This process was augmented with other strategies such as snowballing and opportunistic strategies ${ }^{56,59}$. This enabled both subjects and others close to the research project to recommend further people to contact as possible subjects. "Can you think of anyone else that would be good to interview?" was asked at the end of the most of the interviews to find further subjects. Using these techniques, twenty-two subjects were identified.

The diversity of the subjects was important from the point of view of both the research approach and the generalisability of the final results. Each criterion was broken into different categories aimed at reflecting the diversity of interest. The criteria used were:
1. Industry Sector
2. Project Scale
3. Geographic Location
4. Type of Client
5. Stakeholder Group
6. Professional Discipline
7. Years of Experience with Design
8. Formal Training in Sustainable Design
9. Gender

Table 1 presents the subjects and how each fit the diversity criteria. The numbers associated with each participant represent only the order in which they were interviewed.

\section{Industry Sector}

The industry sector or sectors in which the participant had experience served as the main source of diversity. This was because of the significantly different conditions and challenges that the different sectors face. This criterion was used to obtain a spread throughout the categories of 
Construction, Community / Building, Resources, Product / Manufacturing, Education or Individuals of Interest. As the experiences of the subjects had to relate to engineering operations, the industry sectors chosen were inclusive of almost all engineering work in the area of sustainable design. It also included education, as some engineers in the education sector have experience with sustainable design through previous industry experience, consulting work, or researching of sustainable design practice. Individuals were also identified to be of interest if they had many experiences with sustainable design, but not from one particular industry sector.

Table 1: Diversity of Subjects

\begin{tabular}{|c|c|c|c|c|c|c|c|c|c|c|c|c|c|c|c|c|c|c|c|c|c|c|c|c|}
\hline \multicolumn{2}{|l|}{ Number } & 1 & 2 & 3 & 4 & 5 & 6 & 7 & 8 & 9 & 10 & 11 & 12 & 13 & 14 & 15 & 16 & 17 & 18 & 19 & 20 & 21 & 22 & \\
\hline \multicolumn{2}{|l|}{ Participant } & 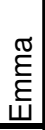 & \begin{tabular}{|l}
$\frac{0}{0}$ \\
$\frac{0}{0}$ \\
$\frac{0}{x}$ \\
\end{tabular} & $\frac{\frac{\bar{d}}{ \pm}}{\sum^{\frac{\pi}{3}}}$ & $\stackrel{\widetilde{\sigma}}{\stackrel{\Xi}{\nu}}$ & $\begin{array}{l}\text { 융 } \\
\text { ర్ } \\
\stackrel{T}{\longrightarrow}\end{array}$ & 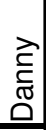 & 들. & 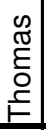 & 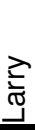 & 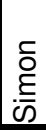 & 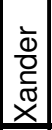 & \begin{tabular}{|c|}
$\frac{\lambda}{0}$ \\
$\mathbb{0}$ \\
0
\end{tabular} & $\frac{.00}{\bar{D}}$ & $\underset{\mathrm{e}}{\mathrm{⿺}}$ & $\begin{array}{l}3 \\
\frac{2}{1} \\
0 \\
\\
\end{array}$ & $\begin{array}{l}\mathscr{U} \\
\mathbb{W} \\
\mathscr{W} \\
\end{array}$ & \begin{tabular}{|l}
$\frac{1}{\Phi}$ \\
$\frac{\Phi}{\Phi}$ \\
0
\end{tabular} & $\underline{\overline{\bar{d}}}$ & $\begin{array}{c}\frac{\mathfrak{\sigma}}{0} \\
\frac{\mathrm{O}}{4} \\
\end{array}$ & $\stackrel{\underset{\varpi}{\infty}}{\sum^{\infty}}$ & $\begin{array}{l}\frac{0}{\pi} \\
\frac{\pi}{\pi} \\
\frac{\pi}{L}\end{array}$ & 竞 & $\begin{array}{l}\frac{\pi}{0} \\
\end{array}$ \\
\hline \multirow{6}{*}{ Industry Sector } & Con & & & & & & & & & $x$ & & $x$ & $x$ & $x$ & & & & $x$ & & & & & & 5 \\
\hline & ComB & $x$ & & & $x$ & $x$ & & & $x$ & $x$ & $x$ & & & & $x$ & & & $x$ & $x$ & & & & $x$ & 10 \\
\hline & Res & & $x$ & $x$ & & & & & & & & $x$ & $\mathrm{x}$ & & & $\mathrm{x}$ & & & & & & & & 5 \\
\hline & Prod & & & & & & $x$ & $x$ & & & & & & & & & $x$ & & & & $x$ & $x$ & & 5 \\
\hline & Indiv & $\mathrm{x}$ & & & & & & & & & $x$ & & $\mathrm{x}$ & & & $x$ & & & & $x$ & & $x$ & & 6 \\
\hline & Edu & $x$ & & & & & $x$ & & & $x$ & & & & $x$ & & & & & $x$ & $x$ & & $x$ & & 7 \\
\hline \multirow{3}{*}{ Project Scale } & Comp & & & & & & & & & $x$ & & $x$ & $\mathrm{x}$ & & & $\mathrm{x}$ & & & & & & & $x$ & 5 \\
\hline & Large & $x$ & $x$ & $x$ & $x$ & & & $x$ & $x$ & $x$ & $x$ & & & $x$ & $x$ & $x$ & & $x$ & $x$ & $x$ & & $x$ & $x$ & 16 \\
\hline & Small & & & & & $x$ & $x$ & $\mathrm{x}$ & $\mathrm{x}$ & $\mathrm{x}$ & & & & & & & $\mathrm{x}$ & & & $x$ & $\mathrm{x}$ & $x$ & & 9 \\
\hline \multirow{3}{*}{$\begin{array}{c}\text { Geographic } \\
\text { Location }\end{array}$} & Rural & & $x$ & $x$ & $x$ & & & & $x$ & $x$ & & & & $x$ & $x$ & $\mathrm{x}$ & & & $x$ & & & & & 9 \\
\hline & Metro & $x$ & $x$ & $x$ & $x$ & $x$ & $x$ & $x$ & $x$ & $x$ & $x$ & $x$ & $x$ & $x$ & $x$ & $\mathrm{x}$ & $x$ & $x$ & $x$ & $x$ & $x$ & $x$ & $x$ & 22 \\
\hline & Inter & & & $x$ & & & & & & $x$ & & $x$ & $x$ & & & $\mathrm{x}$ & $x$ & & $x$ & & $x$ & & & 8 \\
\hline \multirow{3}{*}{ Type of Client } & Pub & & & & & & & & & $x$ & $x$ & $x$ & $x$ & & & & & $x$ & & & & & $x$ & 6 \\
\hline & $\mathrm{P} / \mathrm{P}$ & & & & & & & & & & & $x$ & $x$ & & $x$ & & & $x$ & & & & & & 4 \\
\hline & Pri & $x$ & $x$ & $x$ & $x$ & $x$ & $x$ & $x$ & $x$ & $x$ & $x$ & $x$ & $x$ & $x$ & $x$ & $\mathrm{x}$ & $x$ & $x$ & $x$ & $x$ & $x$ & $x$ & $x$ & 22 \\
\hline \multirow{5}{*}{$\begin{array}{c}\text { Stakeholder } \\
\text { Group }\end{array}$} & Indus & $x$ & $x$ & $x$ & $\mathrm{x}$ & $x$ & & $\mathrm{x}$ & $x$ & $x$ & & $\mathrm{x}$ & $\mathrm{x}$ & $x$ & $x$ & $\mathrm{x}$ & $\mathrm{x}$ & $x$ & $x$ & & $\mathrm{x}$ & $x$ & $x$ & 19 \\
\hline & Gov & & $x$ & $x$ & & & & & & $x$ & $x$ & & & & & & & $x$ & & & & & & 5 \\
\hline & Uni & $x$ & $x$ & $x$ & & $x$ & $x$ & & & $x$ & & & & $x$ & & & & & $x$ & $x$ & $\mathrm{x}$ & $x$ & & 11 \\
\hline & Prof & $x$ & & & & & & & & $x$ & & & & & & & & & & & & & & 2 \\
\hline & NGO & $x$ & & & $x$ & & & & & & & & & & & & & & $x$ & & & & & 3 \\
\hline \multirow{2}{*}{$\begin{array}{c}\text { Professional } \\
\text { Discipline }\end{array}$} & Eng & $x$ & $x$ & $x$ & $x$ & $x$ & $x$ & & & $x$ & & $x$ & $x$ & & & $x$ & $x$ & $x$ & & & & $x$ & $x$ & 14 \\
\hline & Non & & & & & & & $x$ & $x$ & & $x$ & & & $x$ & $x$ & & & & $x$ & $x$ & $x$ & & & 8 \\
\hline \multirow{3}{*}{$\begin{array}{c}\text { Years of } \\
\text { Experience } \\
\text { with Design }\end{array}$} & $<5$ & & $x$ & & $\mathrm{x}$ & & & $\mathrm{x}$ & & & & & $x$ & $x$ & & & & & & $x$ & & & & 6 \\
\hline & $5-15$ & $x$ & & $x$ & & & $x$ & & & & & & & & & $\mathrm{x}$ & $\mathrm{x}$ & & $x$ & & $\mathrm{x}$ & $x$ & & 8 \\
\hline & $16+$ & & & & & $x$ & & & $x$ & $x$ & $x$ & $x$ & & & $x$ & & & $x$ & & & & & $x$ & 8 \\
\hline \multirow{2}{*}{$\begin{array}{c}\text { Formal } \\
\text { Training of SD }\end{array}$} & $\mathrm{Y}$ & $x$ & & & $x$ & $x$ & & $x$ & $x$ & & & $\mathrm{x}$ & & & & & & $x$ & $x$ & $x$ & $\mathrm{x}$ & & & 10 \\
\hline & $\mathrm{N}$ & & $x$ & $x$ & & & $x$ & & & $x$ & $x$ & & $x$ & $x$ & $x$ & $\mathrm{x}$ & $x$ & & & & & $x$ & $x$ & 12 \\
\hline \multirow{2}{*}{ Gender } & $\mathrm{F}$ & $x$ & & & $\mathrm{x}$ & & & & & & & & & $x$ & $x$ & & & & $x$ & $x$ & & $x$ & & 7 \\
\hline & $\mathrm{M}$ & & $x$ & $x$ & & $x$ & $x$ & $x$ & $x$ & $x$ & $x$ & $x$ & $x$ & & & $\mathrm{x}$ & $x$ & $x$ & & & $x$ & & $x$ & 15 \\
\hline
\end{tabular}

\section{Project Scale}

The project scale was included as subjects working on smaller scale projects were predicted to have vastly different experiences compared to those working on large, multi-national projects. The categories used were complex, large and small, and reflected the size and associated cost of the solution being developed. Complex projects were mainly international or multi-national, 
many-million dollar projects, or projects that had many different disciplines working together on a solution with many smaller facets. Large projects were multi-million dollar projects that consisted of work on a single entity, be it a building, a mine or a plant that had different disciplines working together. Small projects were smaller single entities that were typically less than a million dollars in value. These could take the form of a house, a car or a domestic appliance. The categories were not regarded as mutually exclusive; that is, a participant may have experience in all three categories.

\section{Geographic Location}

Geographic location, while similar to the scale of projects in terms of the diversity it can provide, is important as local conditions and cultures can have an impact on the subjects' experiences of sustainable design. The categories for the geographic location were rural, metropolitan and international, with a participant able to have experiences in any number of these. Rural referred to projects outside major cities, metropolitan, projects within major cities, and international to projects with links outside Australia.

\section{Type of Client}

The type of client was included as the challenges in a publicly versus privately funded project were predicted to be vastly different, particularly with respect to sustainable design. The three categories used were public projects, public - private partnership projects, or private projects. It should be noted that these three were not regarded as mutually exclusive; that is, a participant may have experience in all three categories. Public projects were those that had government sources of funding and were for government works, either at a federal, state or council level. Private projects were run by a private corporation. Public - private partnerships were projects where funding came from both the private and the public sector, and are typically larger, more complex projects.

\section{Stakeholder Group}

The stakeholder group was another important diversity indicator, and represented the different group or groups that the participant was associated with. The major stakeholder groups used for this study were industry, government, education, the engineering profession, and non-government organizations. Industry represented people in private companies involved with engineering operations. Government included both government representatives and engineers working for the government rather than a private entity. Education included academics or other research staff involved with educating students or research in sustainable design within a university context. The engineering profession included people who had particular roles within professional organizations, rather than simply membership of those organizations. Non-government organizations (NGOs) included people who may be involved in another group as a professional, but also be part of a NGO oriented towards sustainability issues. It was predicted that people from these different groups would have diverse experiences of sustainable design.

\section{Professional Discipline}

In order to look beyond the current practice of engineers, a number of non-engineers, still involved with engineering design activities, were included under the professional discipline criterion. These non-engineers included architects, environmental scientists and industrial designers. These categories were considered mutually exclusive. In the case of a participant who was both an engineer and architect, their placement depended on which group the participant 
identified with. A ratio of two thirds engineers to one third non-engineers was desired to reflect the emphasis on engineering projects but also incorporating other disciplines.

\section{Years of Experience}

The years of experience in design was included so as to maximize the variation of professional experience of the subjects. Experience of design, and not sustainable design, was used to allow for the fact that a participant may be an experienced designer but have relatively little experience of sustainable design. Conversely, it was thought that the less experience the participant had, the less they may be fixed to a certain 'way of doing things' and thus could be more open to dealing with sustainable design issues. It was anticipated that roughly a third would come from each of the three levels of interest. These were defined as $1-5$ years experience (level 1), $5-15$ years experience (level 2), and 15 + years experience (level 3). These were regarded as mutually exclusive categories. This criterion was used as an introductory question in the interviews to develop an understanding of the background of each participant.

\section{Formal Training in Sustainable Design}

Formal training in sustainable design was a yes or no category and was determined by a preliminary question in the interviews. This also helped to develop a clearer picture of the participant's background and possible knowledge base about sustainable design. This was important because of the possibility of the participant giving an academic definition of sustainable design, based on what they had been taught, rather than their experiences of sustainable design.

\section{Gender}

Gender was the final criterion and identified as an important source of variation in ways of experiencing an aspect of the world ${ }^{60}$. The percentage of females in engineering in Australia is currently about five and a half percent, and about fifteen percent in engineering education programs $^{61}$. When selecting subjects, at least fifteen percent female was the target, in line with these trends. However, as the sample was not meant to be representative of the population, having a minimum of fifteen percent female was as much an ethical issue as a source of diversity $^{62}$. The final sample contained just over thirty percent female (seven out of twenty-two), which again was not representative but gave arguably a greater diversity of experiences than just fifteen percent female.

These criteria were used throughout the selection process of subjects and were kept in mind as new subjects were identified to ensure that a diverse final group was obtained. The position of the participant in most of the categories was derived from the experiences talked about in the interview or through prior contact, except for the years of experience with design activities and formal training in sustainable design, as these were ascertained in the beginning of the interview.

\section{Collection of Data}

The data collection consisted of twenty-two semi-structured, in-depth interviews, conducted with each of the identified subjects. Pilot interviews were conducted to gain experience with the interviewing technique, and to test the interview protocol ${ }^{43,51}$. Two pilot interviews were conducted with colleagues using a preliminary interview protocol. The colleagues involved had some experience with sustainable design. Their interview transcripts were not included in the 
main research study, and used only to refine the interview technique and protocol. Through this process, the interview technique, as well as the interview protocol itself, was enhanced.

After the pilot interviews were completed, the twenty-two subjects were contacted by letter with a follow up telephone call or email explaining the study, what their involvement in the study would entail, and that the study had been approved by an ethics committee of the University. Once contacted, a date, time and place were set for each interview. Only one person approached declined to be involved. Most interviews took place either in the participant's office or in a private room at the University, whichever was easier for the participant. In some cases, a third venue was found, as the interview was conducted away from both the University and the participant's work environment. Arrangements were made to minimize possible interruptions, especially when the interviews were conducted in the participant's office. On average, the interviews lasted forty-five minutes, but ranged between half an hour to up to an hour and a quarter, depending upon how much time the participant had available and the flow of the discussion.

A set of semi-structured, open ended questions were used within the interview protocol, with follow up questions seeking clarification of terms and ideas the interviewee relayed. The interview protocol also helped to ensure proper phenomenographic practice, and tried to capture some of the diversity criteria of the interviewee. Additional follow-up questions asked spontaneously during the interview encouraged the subjects "to give full explanations of their understanding by nondirective questions such as 'Could you explain that further?', 'What do you mean by that?', 'Is there anything else you would like to say ...?",46(p263). Within the interview, it was important that the subjects talk about their experiences with sustainable design, and that they were not led into some kind of 'meta-talk' about issues ${ }^{63}$, providing either corporate rhetoric or baseless speculation.

The body of the interview made up the core data for the research. The subjects were asked to describe an experience they had that involved sustainable design. They were not confined to talking about a particular experience, because the experiences they selected to discuss help to illustrate the way they experience sustainable design. The follow up questions in this part of the interview were all aimed at eliciting what was meant by certain words or concepts the subjects used, instead of assuming what was implied. The subjects were asked directly to describe what they meant by terms used, and in many cases, how important they considered them for sustainable design. Throughout the interview, it was ensured that the subjects kept talking about their experiences, and what their role was, rather than describing generally what was done by others.

\section{Data Analysis}

The data analysis process undertaken was an iterative one, constantly grounded in the interview data. Once the interviews were recorded, they were transcribed verbatim. This verbatim transcription was important, as not only was what the participant said significant for the phenomenographic process, but also how they said it and in what context. The same term or phrase could be used in different contexts to mean different things by different subjects, or conversely different subjects may use different terms or phrases to mean similar things. In phenomenographic analysis, the context of utterances is important ${ }^{64}$. The transcripts were de- 
identified as they were transcribed. Each participant was given a pseudonym that was used during the subsequent analysis and presentation of the findings.

The first step in the analysis of the transcripts involved trying to develop a statement of each individual's way of experiencing sustainable design. The transcribed interviews were all read and re-read to familiarize myself with each transcript. As a transcript was read through, the statement 'Sustainable design is...' was kept in mind to try to develop a statement of what sustainable design was for that person. Critical statements about sustainable design were identified throughout the transcript, and while these helped focus the analysis process, they were used within their context in the transcript as a whole. These statements were identified as they demonstrated a key aspect of how the subjects related their experiences of sustainable design.

In a first attempt, ways of experiencing sustainable design were identified for the twenty-two transcripts. For example, the statement derived from Larry's transcript was "Sustainable design is a holistic process of designing efficient solutions to problems that takes into account responsibilities to society and the environment." The focus that Larry has on a holistic design process is central to what sustainable design is for him. Henry's way of experiencing sustainable design was identified as "Sustainable design is an approach on both a professional and personal level to understand processes simultaneously at a holistic, systems level and at a detailed level, in order to have a restorative effect on the environment and society." The ways of experiencing sustainable design for all twenty-two transcripts, each backed up with a set of illustrative quotes, became the basis for the evolution of the categories of description of sustainable design.

The ways of experiencing sustainable design for each transcript were compared, looking for similarities and differences that would reveal key, qualitative variations in this aspect of the world. Transcripts were grouped by key similarities and differences in the individual way of experiencing sustainable design. The structure of the variations also started to become apparent and was used to further examine the variations between categories. For example, both Henry and Larry have a focus on sustainable design as a holistic process. Henry, however, sees sustainable design as not just taking into account the responsibility of engineers in the design process, as Larry does, but on designs having a restorative effect on the environment and society. These similarities and differences became the basis of the next step of the analysis process, in which similar ways of experiencing sustainable design were grouped in forming draft categories of description.

The first major difference that became apparent from the interviews was the focus on either finding a solution or solving a problem. For those subjects who talked about sustainable design as finding a solution, the solution itself took the form of either a final physical product or the processes in developing a product. The product / process variation came from the variation in experiences of the subjects. The product engineers talked about the product, for example a refrigerator or a car, whereas the process engineers talked about the processes of producing the final product, for example the processes to produce a refined metal, or a petroleum product. For those that talked about solving problems, the problems discussed were either those supplied by a client, or the client's problem seen as part of a larger set of social problems. There was a group of transcripts in which sustainable design was spoken of as not just solving problems as a designer, but as a person. Sustainable design was a way of framing lives, and these subjects talked about experiences of sustainable design applied within their lives. This included designing their own 
house, or encouraging others to adopt sustainable practices in their lives. This group of transcripts was also seen from a structural point of view to be more comprehensive than the others. The subjects were not only talking about sustainable design as a professional activity in the way the others were, but as a personal framework.

Once the groupings had been developed, the transcripts that made up each were analyzed again and a statement explaining the commonality was developed. Each statement was illustrated with quotations taken from the transcripts. The descriptions of the groupings related to the transcripts in the grouping only, and made no mention of or comparison to the other groupings. As the descriptions of the categories were tightened and reviewed, the distribution of the transcripts across the categories was modified. During this time, diagrams for each of the categories of description were developed. After the categories of description had been further refined, labels were developed for the five categories to help in their presentation. The diagrams were also refined, and illustrative quotes were chosen to further illustrate each category.

\section{Results}

The outcome space presented in Table 2 represents a summary of the five qualitatively different ways of experiencing sustainable design derived from the interview transcripts. Three major structural groupings were identified for the categories of description, those of solution focused, problem focused and social network focused approaches to sustainable design.

Table 2: Outcome Space for Sustainable Design

\begin{tabular}{|c|l|}
\hline Category Name & \multicolumn{1}{|c|}{ Description } \\
\hline \multicolumn{1}{|c|}{ Solution Focused } \\
\hline $\begin{array}{c}\text { Category 1 } \\
\text { Solution Finding }\end{array}$ & $\begin{array}{l}\text { Sustainable design is finding a solution, either a product or process(es), to satisfy a } \\
\text { client's declared requirements while decreasing the associated environmental, social } \\
\text { and economic impacts. }\end{array}$ \\
\hline \multicolumn{1}{|c|}{ Problem Focused } \\
\hline $\begin{array}{c}\text { Category 2 } \\
\text { Reductionist Problem } \\
\text { Solving }\end{array}$ & $\begin{array}{l}\text { Sustainable design is the process of identifying and solving a client's problem by } \\
\text { taking a reductionist approach to making decisions that each decrease the associated } \\
\text { environmental, social and economic impact. }\end{array}$ \\
\hline $\begin{array}{c}\text { Category } \mathbf{3} \\
\text { Holistic Problem } \\
\text { Solving }\end{array}$ & $\begin{array}{l}\text { Sustainable design is the process of identifying and solving a client's problem } \\
\text { holistically on a systems level, to increase the environmental, social and economic } \\
\text { value of the solution. }\end{array}$ \\
\hline \multicolumn{1}{|c|}{ Social Network Focused } \\
\hline $\begin{array}{c}\text { Category 4 } \\
\text { Social Network } \\
\text { Problem Solving }\end{array}$ & $\begin{array}{l}\text { Sustainable design is the process of identifying and solving a client's problem as part } \\
\text { of a network of wider problems facing society to increase the environmental, social } \\
\text { and economic value of the solution to both the client and society. }\end{array}$ \\
\hline Category 5 & $\begin{array}{l}\text { Sustainable design is a way of life where all design problems, professional and } \\
\text { personal, are solved to increase the environmental, social and economic value of the } \\
\text { outcome to both the individual and society. }\end{array}$ \\
A Way of Life
\end{tabular}

The solution focused group looks at finding a specific solution within the already declared requirements of the design. The distinction between solution focused and problem focused is the change from looking to find a solution to a client's already declared requirements, to identifying 
in collaboration with the client, what the client's problem actually is and developing the requirements from that to find a solution. Social network focused takes this a step further with the designer looking at the client's problem within the context of a larger set of problems facing society, and finding a solution as much for the larger set of problems as for the client's problem.

The five categories of description presented represent five qualitatively different ways of experiencing sustainable design among the twenty-two subjects interviewed in the study. There is a relationship between the categories in the form of a hierarchy, from less comprehensive to more comprehensive in terms of both the aspects the categories include and the linkages between these aspects. The hierarchy of the categories can be seen in Figure 4. It presents both similarities and variations between the categories of description of sustainable design.

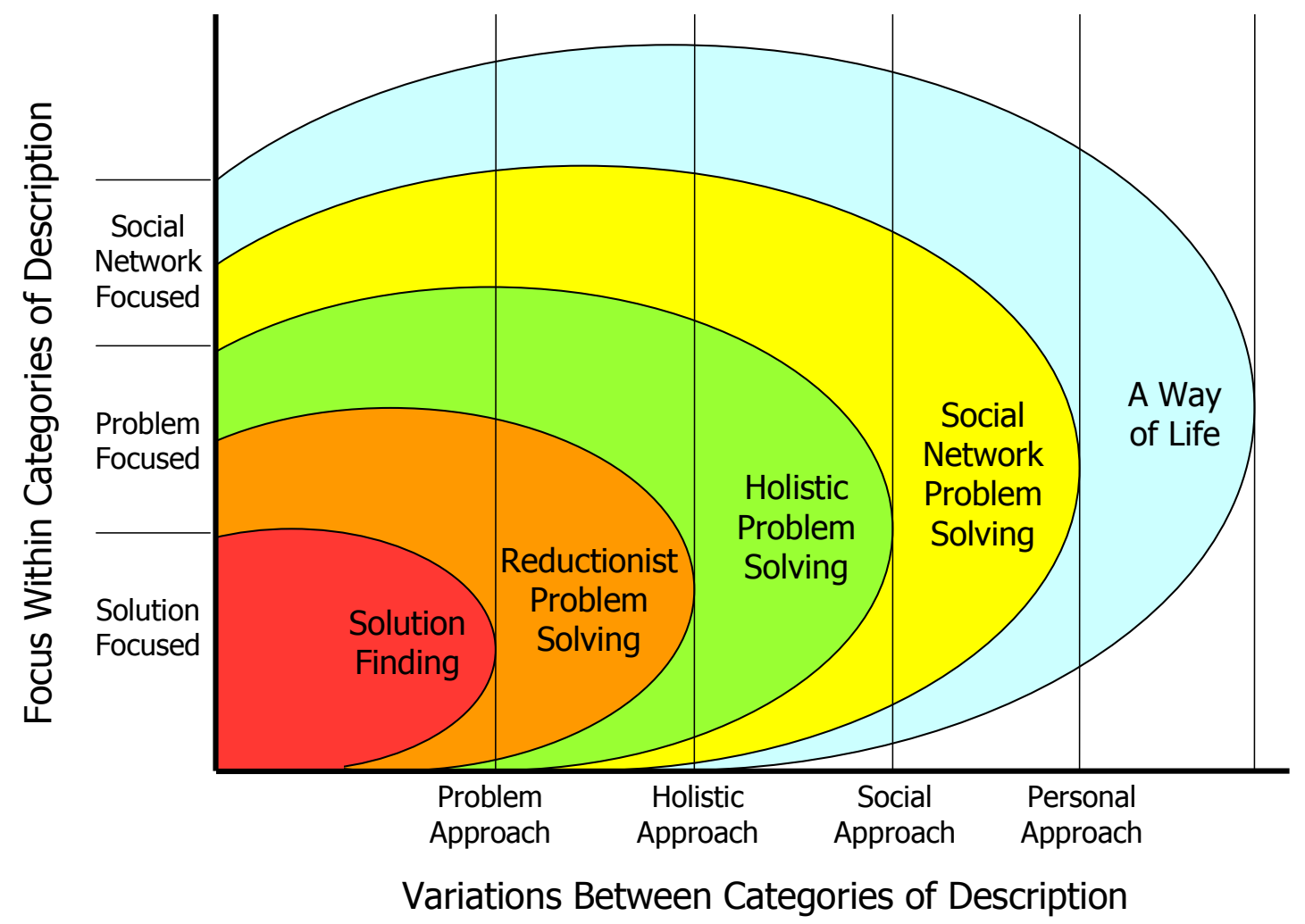

Figure 4: Relationships between Categories of Description

The five categories have between them three different focuses; solution focused categories, problem focused categories and social network focused categories. As the categories become more comprehensive, the focus within the category broadens, effectively increasing the scope of the solution that can be found. The solution focused category is just looking for the solution within the client's declared requirements. A solution is found solely to fit with the requirements, as that is all that matters to the designer. The problem focused categories widen the available scope of solutions by reconsidering the client's problem in collaboration with the client, and jointly determining the final requirements of the solution. This enables other possible solutions to be proposed that solve the client's problem, but that may not have been allowable within the initial client's requirements. The social network focused categories take the focus on the problem a step further, but looking not just at the client's problem, but at the network of problems facing 
society that surround and influence the client's problem. The solutions that are found are done so within the broader framework of the social network.

The main variations between the five categories of description involve the approach the designer takes. While the focus within the category is also a point of variation, it shows more the similarities between categories than the differences. They are linked however, in that the approach the designer takes enables them to have a different focus within the category. The four different approaches that distinguish the different categories are a problem approach, a holistic approach, a social approach, and a personal approach. The problem approach echoes the change from finding a solution to looking at the problem. The holistic approach is a move from making design decisions in a reductionist way to making them in a holistic way, with the focus still on the problem. The social approach echoes the move from looking just at the client's problem to looking at the client's problem within the larger network of social problems. Finally, the personal approach is the move from considering sustainable design problems externally, to seeing them on a personal level with the designer as a part of society. This results in sustainable design being seen as a way of life, as opposed to a way of designing, which is what the four previous categories refer to.

Validity

Two types of validity were used in this study, those of communicative validity, and to some extent, pragmatic validity. Sandberg ${ }^{65}$ proposes three phases in the phenomenographic process where communicative validity is relevant: (i) within the interviews communicating with the subjects; (ii) in the analysis process communicating with the text; and (ii) in communicating the results to other researchers and professionals.

For the first phase of communicative validity within the interviews, subjects were informed prior to the interview that the researchers were interested in their experiences of sustainable design. They were also informed that there were no right or wrong answers, and that no personal judgments would be made about what was discussed. This was to start to develop a joint understanding between the subjects and the researchers about what was being discussed in the interview $^{65}$. The other aspect of communicative validity in this phase was establishing a dialogue within the interview, rather than the interview becoming a question and answer session. This was achieved by having a specific interview protocol with a set of open ended initial and follow up questions to stimulate discussion, rather than asking questions of a closed nature. Also, within the interviews, the subjects were constantly asked to qualify the statements they made as a way to stimulate further discussion.

The second phase, during the analysis process, involved focusing on the transcripts as wholes, rather than trying to extract parts of the transcripts and analyze them out of context. This focus was maintained by looking at the similarities and differences between whole transcripts, especially where a particular statement taken out of the transcript may appear to fit into one category, but when seen within the whole transcript fits into another category.

The third phase of communicative validity involved obtaining feedback from other researchers and professionals. The results were communicated and developed with other researchers in the field. The feedback was positive in that the results seemed to make sense from engineering, design and sustainable design perspectives. 
The results were also communicated to a group of fifteen practising sustainable designers, both engineers and non-engineers. While two of the subjects interviewed to generate the categories of description were present, it was not the focus of the feedback to validate their placement within the categories. The general group responded positively to the categories, and understood that they showed that while everyone was 'doing sustainable design' there are still differences based upon individuals' previous experiences. The practicing engineers could also see implications for the practice of sustainable design, particularly with the change in focus from finding a solution to solving a problem, as well as seeing problems within a wider societal context. This feedback from the group of professionals was also relevant to the pragmatic validity of this study. While pragmatic validity usually involves applying the outcomes of research in practice and seeing whether or not practice has improved, this is outside the scope of this study. However, the group of professionals could see how the results could be applied to their own practice.

$\underline{\text { Reliability }}$

Reliability in this phenomenographic study revolved around the researchers' interpretive awareness, or how interpretations have been controlled and checked throughout the research process $^{45,64}$. The stages in the study where this was done were in:

1. The formulation of the research questions;

2. The selection of the subjects;

3. Interviewing those subjects;

4. Analyzing the resultant transcripts;

5. Reporting the final categories of description.

1. The research questions for this study aimed to elicit the variations that existed among practitioners' experiences of sustainable design. Of the three research questions, the first asked what were the variations in ways of experiencing 'sustainable design' among the sustainable design practitioners interviewed. The other two questions concerned the implications of the results from the first question for sustainable design practice and sustainable design education. The questions were formulated with a focus on exploring variation in ways of experiencing sustainable design, rather than trying to test or impose a preconceived theory.

2. In selecting the subjects, a set of specific criteria were used to ensure variation in the experiences of the subjects. These criteria were developed from the literature and ensured that participants were not selected based upon what the researchers believed sustainable design to be. Rather, most of the subjects were identified either as leaders in the practice of sustainable design through awards and the like, or identified by others in the field as persons of interest.

3. During the interview process, the researchers' interpretations were controlled and checked in a number of ways. Before interviews began, two pilot interviews were conducted to develop interviewing skills as well as the interview protocol. The interview protocol was also developed so as not to ask leading questions, or questions that suggested a particular way of experiencing sustainable design to the interview subjects. The interview protocol also aided in making the interviews as consistent as possible. Each interview started with the same information and introductory questions, and ended with the same concluding questions. During the interviews, an open-ended but focused interviewing technique was used. This allowed the subjects to focus on 
the aspects of sustainable design they believed were important rather than 'fitting in' to any preconceived theories.

4. In the analysis process, the main control of the researchers' interpretations was a strict adherence to data, in the form of the twenty-two interview transcripts. This involved constantly going back to the data as a whole, and reading statements in context. It also involved admitting to inconsistencies between transcripts during the analysis process, rather than trying to constrain the data to appear consistent. The categories were developed in an iterative fashion, in which the inconsistent transcripts acted as prompts for a different way of viewing the categories of description.

5. The final results are in the form of a set of categories of description that form a hierarchical outcome space. The descriptions of the categories are based on the transcripts, and include illustrative quotes taken from some of the transcripts to further check the researchers' interpretations.

\section{Implications for Professional Education}

The main contribution of this research is in highlighting the need to change the way professional development in engineering is understood in practice, both for students at university and professionals in the workplace. This change involves developing students' and practitioners' embodied ways of experiencing sustainable design practice, along with their engineering skills, to form their professional way-of-being. Developing this professional way-of-being will allow students and professionals to engage in practice as competent professionals ${ }^{13,18}$. It will also enable them to deal with the "complexities, ambiguities, and dynamic change inherent in professional practice"17 ( $\mathrm{p} 401)$, as how people understand practice is central to how they perform in that practice ${ }^{18,65,66}$. Seeing professional development in this way has implications for the organization of future engineering professional development efforts. In particular, the implications are for the focus of learning, curriculum design and the design of learning environments, both at university and for professionals undergoing professional development.

\section{Focus of Learning}

There needs to be a shift away from the transfer of knowledge, skills, attitudes and values, to developing a professional way-of-being, incorporating both engineering skills development, such as problem solving or design, and a way of experiencing practice. Providing students with more and more decontextualised knowledge, skills, attitudes and values, will mean they will incorporate these into their current ways of experiencing practice. This also gives rise to a gap between the ways they deal with 'clear cut' problems presented at university, and the 'messy' problems of professional practice. "Knowledge and skills must become embedded within the understanding of professional practice being formed" ${ }^{18}$ (p689). Engineering education requires a paradigm shift to developing this integrated professional way-of-being, rather than learning content decontextualised from practice.

For example, the current way of teaching engineers about technical communication in the US is through a separate course, usually taught by an academic from another faculty ${ }^{67}$. However it is argued that "such courses... are of little use and in fact there is a considerable risk of students ending up weaker in areas they were supposed to become better at"68. This is because what is 
learnt within a course is just as important as how it is learnt. Thus courses that separate, for instance, technical communication from learning about the practice of engineering do not develop the students understanding of practice.

The more comprehensive ways of experiencing sustainable design that were identified will enable students to deal more effectively in practice. It is argued that developing more comprehensive ways of experiencing sustainable design within students will enable them to deal with the complex, 'messy' problems many will face as engineers in the future. Thus, we should aim to develop more comprehensive ways of experiencing sustainable design within students. It must be remembered however that this development is not a stepwise movement between ways of experiencing practice, but a continuum. The more comprehensive ways of experiencing practice need to become the basis of structuring engineering programs.

Another implication for the education and professional development of engineers about sustainable design is the need to constantly monitor how sustainable design is experienced by all, including students, academics and professionals. This information is a vital input into the design and continual improvement of educational curricula, learning environments and assessment ${ }^{17}$. Thus changes in ways of experiencing, especially in engineering practice, need to be captured and integrated, and should become the focus of learning in educational institutions.

\section{Curriculum Design}

An implication for curriculum design is that experiences need to be offered to enable students to develop their own way of experiencing professional practice. Opportunities need to be given to students throughout the curriculum to question and extend their current way of experiencing sustainable design practice and develop skills. One way of approaching this is to expose students to the ways of experiencing we want them to develop ${ }^{69}$. For example, exposing students to Category 3, holistic problem solving, may entail posing a problem that requires students to look at the problem in a holistic way, rather than in a reductionist way.

This constant focus on developing experiences of practice needs to be maintained throughout the curriculum, as argued by Dall'Alba \& Sandberg ${ }^{17}$. It is also important that this focus is made explicit to the students involved. It is unlikely that students' ways of experiencing practice are transformed as a by-product of a course or program that does not have this focus throughout. Further, studies show that elements outside the formal curriculum play an important role in students' learning and development as professionals ${ }^{70}$. This notion needs to be considered in the design of future engineering curricula.

\section{Design of Learning Environments}

An implication for the design of learning environments in which curricular are situated is the need to actively engage students in learning processes, encourage students to support and challenge each other's development, and require students to be reflective about what they are doing $^{17}$. Recent educational research has shown how active learning processes are beneficial to student learning. Simply giving the students the 'right' way of experiencing cannot work, but must involve an active interplay between old and new ways. Further, these learning environments need to reflect the variation that is present in practice. The focus needs to be also on the students learning together: "we can use discussion and interaction between students to expose them to the 
meaning which the course content has for other students, and to explore and extend their own ideas through interaction with, and challenges from, others" ${ }^{5}$ (p311).

Education systems also need to take account of the external experiences of their students, in terms of sustainable design and engineering in general ${ }^{70}$. Studies have shown that students often come into professional programs with different ways of experiencing practice already, and curricula need be developed to recognize these experiences ${ }^{17,18}$. Ideally these external experiences are provided to the student as part of their professional formation, either through structured work experience or co-op programs, or through professional placement semesters ${ }^{71,72}$.

\section{Examples of the New Approach}

An example of developing practitioners' ways of experiencing engineering practice is the Master of Sustainable Practice at RMIT $^{73}$. This program aims to develop a 'community of practice' of practitioners, focusing on developing their professional practice of sustainability. The program embeds an action learning model to explore specific projects the students are working on in their professional lives regarding sustainability. In this way, students are encouraged to develop their way of experiencing sustainability as well as engineering skill development.

The development of ways of experiencing professional practice could also begin before students formally start their engineering undergraduate degree. For example, The Engineering Link Group $^{74}$ run two camps for high school students interested in studying engineering. Both the Engineering Link Project ${ }^{75}$ and the Enterprise Management Project (formally the Future Engineers Australia Management Project) ${ }^{76}$ develop students' experiences of engineering practice by the students acting as engineers and engineering entrepreneurs. Each camp is based around day-long activities where groups of students are posed real world engineering problems by practicing engineers, and must create innovative solutions. Focus is maintained on identifying and solving problems as a professional would. In this way, future engineering students can enter engineering programs with more comprehensive ways of experiencing engineering practice.

Sustainability and sustainable design will not be truly embraced in engineering curricula until the academics designing and teaching the curricula embrace the concepts themselves ${ }^{20}$. A vital part of this is the recognition that while sustainable design is informed by science, it is a value-laden concept and thus has to be handled differently than more technical elements of the curriculum. Academics need to be encouraged to learn about sustainability and sustainable design themselves to become better role models for their students ${ }^{21}$. Academics need to not only have an up-to-date understanding of sustainable design in practice as well as being attentive to students' learning requirements, but "be able to teach in a way that takes account of all these [aspects]"17(p402).

\section{Conclusion}

This paper presented a study investigating how a group of leading practitioners have experienced an aspect of engineering practice, namely sustainable design. All engineering students and increasingly practicing engineers are expected to have an understanding of sustainable design and be able to apply it in practice. This paper argues that a professional's way-of-being, incorporating the way they understand aspects of their practice, forms the basis of how they act in practice. Identifying the ways practitioners have experienced sustainable design in the past is a vital step in its widespread education and adoption throughout engineering. 
This paper also argues for the wider use of phenomenography in engineering education research. It provides a means of assessing the impact of engineering education programs by examining the changes to students' ways of experiencing practice, rather than assessing the accumulation of content. On a wider level, this research demonstrates that phenomenography is also useful for investigating aspects of professional practice, specifically in exploring ill-defined topics in professional practice and professional development. Phenomenography provides rich data, and helps to make explicit what is hidden. It not only offers a way of exploring these topics, but also tracking changes in existing areas.

\section{References}

1. Engineers Australia. (2005). Accreditation Criteria Guidelines (No. G02). Barton, ACT: Engineers Australia.

2. Lang, J.D., et al. (1999). Industry Expectations of New Engineers: A Survey to Assist Curriculum Designers. Journal of Engineering Education, 88(1), p43 - 51.

3. Gale, S. (2005). Engineering the Future. Sustainability in Engineering Education and Knowledge (SEEK) A Newsletter for Environmental Engineering Educators from Engineers Australia's College of Environmental Engineers, 1(3), p3 - 4.

4. Williams, P. (2002). Environmental Engineers: Changing Engineering Culture. Paper presented at the 4th Queensland Environmental Conference, Brisbane.

5. Dall'Alba, G. (1993). The Role of Teaching in Higher Education: Enabling Students to Enter a Field of Study and Practice. Learning and Instruction, 3(4), p299 - 313.

6. McLennan, J.F. (2004). The Philosophy of Sustainable Design. Kansas City: Ecotone.

7. Mann, L.M.W., J. Walther, and D. Radcliffe. (2005). Sustainable Design Practitioners: Why They Must be at the Centre of Discussions on Sustainable Design Education. Paper presented at the 2005 ASEE/AaeE 4th Global Colloquium on Engineering Education, Sydney, Australia.

8. Johnston, S.F. (2003). Sustainability and Globalisation: A Positive Role for Engineering. Paper presented at the 14th Annual Australasian Association of Engineering Education Conference, Melbourne.

9. Johnston, S.F. (1997). Sustainability, Engineering, and Australian Academe. Society for Philosophy and Technology, 2(3-4), p80 - 101.

10. Leal Filho, W. (2000). Dealing with Misconceptions on the Concept of Sustainability. International Journal of Sustainability in Higher Education, 1(1), p9 - 19.

11. Marton, F. and S. Booth. (1997). Learning and Awareness. Mahwah, N.J.: L. Erlbaum Associates.

12. Mann, L.M.W., D. Radcliffe, and G. Dall'Alba. (2007). Experiences of Sustainable Design among Practicing Engineers - Implications for Engineering Education. Paper presented at the ASEE Annual Conference \& Exposition, Honolulu, Hawaii.

13. Dall'Alba, G. and J. Sandberg. (1996). Educating for Competence in Professional Practice. Instructional Science, 24, p411 - 437.

14. Dall'Alba, G. and J. Sandberg. (1993). A Competency-Based Approach to Education and Training: Will it Improve Competence? HERDSA News, 15(1), p3 - 5.

15. Dreyfus, H.L. (2002). A Phenomenology of Skill Acquisition as the Basis for a Merleau-Pontian Nonrepresentationalist Cognitive Science, University of California, Berkeley, Department of Philosophy, from http://socrates.berkeley.edu/ hdreyfus/pdf/MerleauPontySkillCogSci.pdf

16. Dreyfus, H.L. and S.E. Dreyfus. (1986). Mind Over Machine: The Power of Human Intuition and Expertise in the Era of the Computer. New York: Free Press.

17. Dall'Alba, G. and J. Sandberg. (2006). Unveiling Professional Development: A Critical Review of Stage Models. Review of Educational Research, 76(3), p383 - 412.

18. Dall'Alba, G. (2004). Understanding Professional Practice: Investigations Before and After an Educational Programme. Studies in Higher Education, 29(6), p679 - 692. 
19. Thom, D. (1998). Engineering Education and the New Industrial Revolution. International Journal of Engineering Education, 14(2), p89 - 94.

20. Harding, R. (1999). Sustainability in the Curriculum: Why and How? - Keynote Address. Paper presented at the 10th Annual Australasian Association of Engineering Education Conference: Unfolding Landscapes in Engineering Education, Adelaide.

21. Crofton, F. and C.A. Mitchell. (1998). Role Models and Environmental Education: The Good, The Bad, and the MIA. Paper presented at the American Society for Engineering Education Annual Conference \& Exposition, Seattle, WA.

22. Paten, C.J.K., et al. (2004). Engineering Sustainable Solutions: Education Program - Putting Sustainability as a 'Critical Literacy' into Mainstream Engineering Curricula. Paper presented at the Engineering Education in Sustainable Development Conference, Barcelona, Spain.

23. Walther, J. and D. Radcliffe. (2006). Accidental Competencies: Is Engineering Education Simply a Complex System? Paper presented at the 17th Annual Conference of the Australasian Association for Engineering Education, Auckland, New Zealand.

24. Lave, J. (1993). The Practice of Learning. In S. Chaiklin and J. Lave (Eds), Understanding Practice: Perspectives on Activity and Context (p.3 - 32). Cambridge: Cambridge University Press.

25. Schön, D.A. (1995). The New Scholarship Requires a New Epistemology. Change, $27(6)$, p26 - 34.

26. Schön, D.A. (1983). The Reflective Practitioner: How Professionals Think in Action. London: Maurice Temple Smith Ltd.

27. Walther, J. and D. Radcliffe. (2006). A Multi-scale Systems Model of Engineering Competence - A Way to Overcome the Competence Dilemma in Engineering Education. Paper presented at the 17th Annual Conference of the Australasian Association for Engineering Education, Auckland, New Zealand.

28. Billet, S. (2001). Knowing in Practice: Re-conceptualising Vocational Expertise. Learning and instruction, $11, \mathrm{p} 431-452$.

29. Marton, F., D. Hounsell, and N. Entwistle (Eds). (1984). The Experience of Learning. Edinburgh: Scottish Academic Press.v

30. Ramsden, P. (2003). Learning to Teach in Higher Education. London: RoutledgeFalmer.

31. Marton, F. (1994). Phenomenography. In T. Husen and T. Postlethwaite (Eds), The International Encyclopaedia of Education (p.4424 - 4429). Oxford: Permagon.

32. Marton, F. and R. Säljö. (1976). On Qualitative Differences in Learning: I - Outcome and Process. British Journal of Educational Psychology, 46, p4 - 11.

33. Marton, F. (1981). Phenomenography - Describing Conceptions of the World Around Us. Instructional Science, 10, p177 - 200.

34. Marton, F. (1981). Studying Conceptions of Reality - A Metatheoretical Note. Scandinavian Journal of Educational Research, 25, p159 - 169.

35. Säljö, R. (1988). Learning in Educational Settings: Methods of Inquiry - Chapter 2. In P. Ramsden (Ed), Improving Learning: New Perspectives (p.32 - 48). London: Kogan Page Ltd.

36. Säljö, R. (1981). Learning Approach and Outcome: Some Empirical Observations. Instructional Science, $10, \mathrm{p} 47-65$.

37. Svensson, L. and J. Theman. (1983). The Relation Between Categories of Description and an Interview Protocol in a Case of Phenomenographic Research. Paper presented at the Second Annual Human Science Research Conference, Duquesne University, Pittsburgh, PA.

38. Dahlgren, L.O. (1984). Learning Conceptions and Outcomes. In F. Marton, D. Hounsell, and N. Entwistle (Eds), The Experience of Learning. Edinburgh: Scottish Academic Press.

39. Marton, F. (1986). Phenomenography - A Research Approach to Investigating Different Understandings of Reality. Journal of Thought, 21(3), p28 - 49.

40. Marton, F. and A. Tsui. (2004). Classroom Discourse and the Space of Learning. Mahwah, N.J.: L. Erlbaum Associates.

41. Pang, M.F. (2003). Two Faces of Variation: On Continuity in the Phenomenographic Movement. Scandinavian Journal of Educational Research, 47(2), p145 - 156.

42. Bowden, J. (2000). The Nature of Phenomenographic Research. In J. Bowden and E. Walsh (Eds), Phenomenography. Melbourne: RMIT University Press.

43. Bowden, J. (2005). Reflections on the Phenomenographic Team Research Process. In J. Bowden and P. Green (Eds), Doing Developmental Phenomenography. Melbourne: RMIT University Press.

44. Trigwell, K. (2000). Phenomenography: Discernment and Variation. Paper presented at the 7th International Symposium on Improving Student Learning, Oxford. 
45. Sandberg, J. (1997). Are Phenomenographic Results Reliable? Higher Education Research \& Development, $16(2), \mathrm{p} 203-212$.

46. Bowden, J., et al. (1992). Displacement, Velocity, and Frames of Reference: Phenomenographic Studies of Students' Understanding and Some Implications for Teaching and Assessment. American Journal of Physics, 60(3), p262-269.

47. Åkerlind, G. (2005). Learning about Phenomenography: Interviewing, Data Analysis and the Qualitative Research Paradigm. In J. Bowden and P. Green (Eds), Doing Developmental Phenomenography. Melbourne: RMIT University Press.

48. Åkerlind, G. (2002). Principles and Practice in Phenomenographic Research. Paper presented at the Current Issues in Phenomenography, Canberra.

49. Åkerlind, G., J. Bowden, and P. Green. (2005). Learning to do Phenomenography: A Reflective Discussion. In J. Bowden and P. Green (Eds), Doing Developmental Phenomenography. Melbourne: RMIT University Press.

50. Cherry, N.L. (2005). Phenomenography as Seen by an Action Researcher. In J. Bowden and P. Green (Eds), Doing Developmental Phenomenography. Melbourne: RMIT University Press.

51. Green, P. (2005). A Rigorous Journey into Phenomenography: From a Naturalistic Inquirer Standpoint. In J. Bowden and P. Green (Eds), Doing Developmental Phenomenography. Melbourne: RMIT University Press.

52. Ashworth, P. and U. Lucas. (2000). Achieving Empathy and Engagement: A Practical Approach to the Design, Conduct and Reporting of Phenomenographic Research. Studies in Higher Education, 25(3), p295 308.

53. Åkerlind, G. (2005). Variation and Commonality in Phenomenographic Research Methods. Higher Education Research \& Development, 24(4), p321 - 334.

54. Hasselgren, B. and D. Beach. (1997). Phenomenography - A "Good-for-Nothing Brother" of Phenomenology? Outline of an Analysis. Higher Education Research \& Development, 16(2), p191 - 202.

55. Bruce, C. (2002). Frameworks Guiding the Analysis: Applied To or Derived From the Data? Paper presented at the Current Issues in Phenomenography, Canberra.

56. Patton, M.Q. (1990). Qualitative Evaluation and Research Methods (Second ed). Newbury Park, CA; London: Sage Publications.

57. Silverman, D. (2005). Doing Qualitative Research (Second ed). Thousand Oaks, CA: Sage Publications.

58. Creswell, J.W. (2003). Research Design: Qualitative, Quantitative and Mixed Methods Approaches (Second ed). Thousand Oaks, CA: Sage Publications.

59. Marshall, C. and G. Rossman. (2006). Designing Qualitative Research (Fourth ed). Thousands Oaks, CA: Sage Publications.

60. Hazel, E., L. Conrad, and E. Martin. (1997). Exploring Gender and Phenomenography. Higher Education Research \& Development, 16(2), p213 - 226.

61. Women in Engineering. (2005). Women in Engineering in Australia. Retrieved 20/06/06, from http://www.engineersaustralia.org.au/./about_us/sig/wie/publications.html

62. National Health and Medical Research Council. (1999). National Statement on Ethical Conduct in Research Involving Humans. Canberra: National Health and Medical Research Council.

63. Säljö, R. (1996). Minding Action - Conceiving of the World Versus Participating in Cultural Practices. In G. Dall'Alba and B. Hasselgren (Eds), Reflections on Phenomenography: Towards a Methodology? -

Göteborg Studies in Educational Sciences (Vol. 109, p.19 - 33). Göteborg: ACTA Universitatis Gothoburgensis.

64. Sandberg, J. (2005). How Do We Justify Knowledge Produced Within Interpretive Approaches? Organisational Research Methods, 8(1), p41 - 68.

65. Sandberg, J. (1994). Human Competence at Work: An Interpretative Approach. Göteborg, Sweden: BAS.

66. Sandberg, J. (2000). Understanding Human Competence at Work: An Interpretative Approach. Academy of Management Journal, 43(1), p9 - 25.

67. Reave, L. (2004). Technical Communication Instruction in Engineering Schools: A Survey of Top-Ranked U.S. and Canadian Programs. Journal of Business and Technical Communication, 18(4), p452 - 490.

68. Bowden, J. and F. Marton. (1998). The University of Learning. London: Kogan Page.

69. Bruce, C., et al. (2004). Ways of Experiencing the Act of Learning to Program: A Phenomenographic Study of Introductory Programming Students at University. Journal of Information Technology Education, 3, p143 -160 . 
70. Walther, J. and D. Radcliffe. (2006). Engineering Education: Targeted Learning Outcomes or Accidental Competencies? Paper presented at the 2006 American Society for Engineering Education Annual Conference, Chicago, IL.

71. Radcliffe, D. (2002). Technological and Pedagogical Convergence Between Work-based and Campus-based Learning. Educational Technology \& Society, 5(2), p54 - 59.

72. Radcliffe, D. (2002). Formal Learning Within a Community of Practice. Paper presented at the 2002 American Society for Engineering Education Annual Conference \& Exposition, Montréal, Quebec.

73. Hadgraft, R. (2006). Master of Sustainable Practice Program Guide. Retrieved 02 / 12 / 06, from http://www.rmit.edu.au/browse;ID=MC153\#description

74. The Engineering Link Group. (2005). The Engineering Link Group: Forging Links Between Schools and Industry. Retrieved 17 / 05 / 05, from http://www.telg.com.au/

75. Millican, G., L.M.W. Mann, and P. Richards. (2005). The Engineering Link Project: Learning about Engineering by Becoming and Engineer. Paper presented at the 2005 ASEE/AaeE 4th Global Colloquium on Engineering Education, Sydney, Australia.

76. Richards, P., L.M.W. Mann, and G. Millican. (2005). Future Engineers Australia Management Project: Turning High School Students into Engineering Entrepreneurs. Paper presented at the 2005 ASEE/AaeE 4th Global Colloquium on Engineering Education, Sydney, Australia. 